\title{
Effects of landscape configuration on the occurrence and abundance of an arboreal marsupial from the Valdivian rainforest
}

Victoria P. Fernández , Gloria B. Rodríguez-Gómez²®D, Dimas A. Molina-Marín ${ }^{3}$, Gabriel J. Castaño-Villa ${ }^{4}$ and Francisco E. Fontúrbel ${ }^{1,5^{*}}$ (D)

\begin{abstract}
Background: Habitat fragmentation and degradation processes affect biodiversity by reducing habitat quantity and quality, with differential effects on the resident species. However, their consequences are not always noticeable as some ecological processes affected involve idiosyncratic responses among different animal groups. The Valdivian temperate rainforests of southern Chile are experiencing a rapid fragmentation and degradation process despite being a biodiversity hotspot. Deforestation is one of the main threats to these forests. There inhabits the arboreal marsupial Dromiciops gliroides, an iconic species from the Valdivian rainforest, it is the only extant representative of the ancient Microbiotheria order, and it is currently threatened by habitat loss. Here we tested the effects of habitat configuration on D. gliroides occurrence and abundance along 12 landscapes of southern Chile with different disturbance levels.
\end{abstract}

Methods: We estimated D. gliroides occurrence and abundance using camera traps and related those metrics with landscape configuration indices obtained from FRAGSTATS (i.e., forest \%, connectivity, patch number, contiguity, and distance to the nearest patch) using Bayesian linear mixed models.

Results: We found that $D$. gliroides occurrence was not influenced by landscape configuration, while its abundance was positively influenced by forest contiguity.

Conclusions: Although this arboreal marsupial is present in disturbed forests, its restricted movement capabilities and high dependency on the forest three-dimensional structure may affect its long-term persistence. We urge to rethink native forest conservation and management policies to improve habitat connectivity with possible positive consequences for native fauna.

Keywords: Abundance, Dromiciops gliroides, Habitat degradation, Habitat fragmentation, Landscape, Occurrence

*Correspondence: fonturbel@gmail.com

${ }^{1}$ Instituto de Biología, Facultad de Ciencias, Pontificia Universidad Católica de Valparaíso, Valparaíso, Chile

Full list of author information is available at the end of the article

\section{Background}

Habitat fragmentation process involves the subdivision of a continuous habitat in several smaller fragments, altering its spatial configuration and increasing edge effects [1-3]. Those habitat fragments are surrounded by a contrasting matrix that may preclude animal dispersal, reducing functional connectivity [4, 5]. Smaller fragments experience area and edge effects (i.e., due to larger 
edge / interior habitat ratios), exposing them to edge species (e.g., exotic herbivores) and human activities [6, 7]. As fragmentation process advances, the extant habitat fragments become smaller and more isolated [8]. The combined effects of area reduction and isolation would negatively affect forest-dependent species that cannot exploit other habitats and are unable to disperse through non-forested habitats, as it happens, for example, with Rhinocryptid birds [9-11], which are threatened by the loss of functional connectivity (i.e., the actual connectivity from the species' perspective, considering specific interactions with landscape structures) among forest fragments [12]. Furthermore, habitat fragmentation is usually accompanied by habitat degradation [13], which implies a reduction in habitat quality due to the scarcity of key structures, such as perches or tree cavities, usually limiting in disturbed habitats [14].

Alterations in habitat structure can change forestdependent species composition and compromise their reproductive success $[15,16]$. However, these species can be differentially affected by habitat fragmentation depending on their response to different landscape features [17]. That is why quantifying the effects of habitat fragmentation on biodiversity is important to understand how landscape-level anthropogenic changes alter the ecological scenario for the resident animal species [18]. Several landscape metrics have been developed to quantify landscape configuration (i.e., area, edge, shape, isolation, contagion, and connectivity), providing a comprehensive framework useful to assess the effects of habitat fragmentation on different focal species [19, 20]. In this regard, FRAGSTATS [21] offers a complete toolkit of landscape configuration metrics for ecologists, which can be used to assess how sensitive species are to habitat fragmentation [22]. Therefore, landscape configuration (i.e., the number of fragments, their size distribution, their shape, and spatial arrangement), which changes due to habitat fragmentation, provides a comprehensive framework to assess its effects on any focal species.

Valdivian temperate rainforests are located in the occidental margin of southern South America (from $37^{\circ}$ to $44^{\circ} \mathrm{S}$ ), and they are considered as a biodiversity hotspot due to their high level of endemism and the presence of relict species [23, 24]. However, these rainforests are among the most threatened ecosystems as a result of anthropogenic pressures, experiencing a rapid fragmentation and degradation due to the expansion of human activities $[25,26]$. Deforestation is one of the main causes of habitat fragmentation, resulting in heterogeneous landscape mosaics, in which the extant native forest remnants are immersed in a contrasting matrix composed of degraded habitats and productive lands, confining most forest species to small and isolated fragments [27, 28].
This is the case of many small mammals and understory birds of these forests, which cannot disperse through non-forested matrices [29-31]. Nevertheless, as most species present idiosyncratic responses [17, 32], it may be very difficult to sort out broad generalizations to make informed decisions and elaborate appropriate management practices.

One of the iconic species of the Valdivian rainforest is the arboreal marsupial Dromiciops gliroides, which is the sole extant living representative of the ancient Microbiotheria order [33], and also the main seed disperser agent at these forests [34]. Due to the high dependence of the forest's three-dimensional structure, $D$. gliroides could be one of the most affected species by habitat fragmentation and degradation. This marsupial is unable to disperse through non-forested habitats [31], and its local abundances are negatively affected by habitat fragmentation and degradation [35, 36]. This species was considered to be restricted to old-growth forests [33], but recently has been found in secondary forests and abandoned forestry plantations $[31,37,38]$ as long as they retain some structural elements that provide movement pathways, shelter, and nesting sites [39]. However, D. gliroides presence at disturbed habitats imply changes in abundance and behavior [40], related to resource availability and vegetation structure [39, 41]. Due to its habitat requirements, D. gliroides may be considered as an umbrella species, as its conservation would benefit many other species of the Valdivian rainforests [42], such as small understory birds.

In this study, we assessed the effects of landscape configuration on $D$. gliroides occurrence and abundance along 12 landscapes of southern Chile, with different disturbance levels. Considering D. gliroides' arboreal habits and its limited movement capabilities through non-forested habitats, we hypothesized that forest cover in the landscape, patch connectivity, and contiguity would be positively related to its occurrence and abundance, while a high number of patches and patch isolation will be negatively related to its occurrence and abundance.

\section{Methods \\ Study area}

We conducted this study at a $450-\mathrm{km}$ latitudinal gradient (from $37^{\circ} \mathrm{S}$ to $41^{\circ} \mathrm{S}$ ), covering ca. $80 \%$ of the Valdivian rainforests in Chile. Along this gradient, we selected 12 landscapes representative of four different levels of habitat disturbance: (1) old-growth native forests (Nahuelbuta National Park, Peumayén Park, and Puyehue National Park), (2) second-growth native forests (Oncol Park north, Huilo Huilo Reserve, and Katalapi Park), (3) native forests under selective logging (Moncopulli, Pucatrihue, and Cascadas), and (4) abandoned forestry plantations of Pinus radiata or Eucalyptus globulus (Forestal 
Mininco, Oncol Park south, and Reserva Costera Valdiviana). We had a balanced design with three landscapes for each habitat disturbance condition (Table S1, available online as Supplementary Material). Those 12 sites were distributed along the Valdivian rainforests (Figure S1), comprising coastal, Andean, and intermediate depression zones. Sampling sites were separated at least $25 \mathrm{~km}$ from each other, except for the two sites at the Oncol Park (representing secondary forest and forest plantation conditions), which were $2 \mathrm{~km}$ apart. A detailed description of the structure and species composition of these 12 study landscapes can be found in Rodríguez-Gómez and Fontúrbel [40].

In Chile, Dromiciops gliroides inhabits the Valdivian forests from the southern end of the Maule Province $\left(35^{\circ} \mathrm{S}\right)$ to the Palena Province $\left(44^{\circ} \mathrm{S}\right)$, as its northern and southern limits were just expanded [43, 44]. Furthermore, Quintero-Galvis et al. [45] recently supported the presence of two Dromiciops species based on genomic analyses, partially confirming the proposal of D'Elia et al. [46]. Therefore, in the light of these new findings, the northern sites (Mininco and Nahuelbuta) would correspond to the new species, D. bozinovici. However, both Dromiciops species are arboreal and depend on forest habitats. For those reasons, we will treat them as a single species for the purposes of this work.

\section{Camera trap assessment}

We used camera traps for estimating $D$. gliroides occurrence and relative abundance at the 12 landscapes. We monitored $D$. gliroides for two consecutive austral summers (December-April) from 2017 to 2019. We deployed 36 infra-red camera traps (Browning Strike Force HD Pro), which were operated in photographic mode with 1-min delay between shots to avoid capturing the same individual multiple times. We installed the camera traps at a height of $1-2 \mathrm{~m}$ above the ground on tree stems, and spaced at least $100 \mathrm{~m}$ from each other. We randomly

Table 1 Dromiciops gliroides occurrence and abundance data obtained from a two-year (2017 and 2018) camera-trap survey. Occurrence values represent the number of camera traps (of a total of 12) with at least one D. gliroides record; occurrence index represents the ratio between occurrence values and the number of camera traps installed. Dromiciops gliroides individuals (Dg ind) were estimated from camera traps after applying a 1-h independence interval. Relative abundances are expressed as the number of $D$. gliroides individuals per day

\begin{tabular}{|c|c|c|c|c|c|c|}
\hline Year & Site & Condition & Occurrence & Occ index & Dg ind & Dg ind/day \\
\hline 2017 & PNN & Native & 8 & 0.667 & 9 & 1.179 \\
\hline 2017 & PNP & Native & 9 & 0.750 & 78 & 0.696 \\
\hline 2017 & PPY & Native & 9 & 0.750 & 101 & 0.902 \\
\hline 2017 & $\mathrm{HHL}$ & Secondary & 4 & 0.333 & 64 & 0.571 \\
\hline 2017 & ONS & Secondary & 10 & 0.833 & 82 & 0.732 \\
\hline 2017 & PKT & Secondary & 10 & 0.833 & 141 & 1.259 \\
\hline 2017 & CAS & Logging & 11 & 0.917 & 90 & 0.804 \\
\hline 2017 & $\mathrm{MCP}$ & Logging & 6 & 0.500 & 34 & 0.304 \\
\hline 2017 & PUC & Logging & 11 & 0.917 & 95 & 0.848 \\
\hline 2017 & FMP & Plantation & 10 & 0.833 & 87 & 0.777 \\
\hline 2017 & ONP & Plantation & 5 & 0.417 & 56 & 0.500 \\
\hline 2017 & $\mathrm{RCV}$ & Plantation & 6 & 0.500 & 34 & 0.304 \\
\hline 2018 & PNN & Native & 10 & 0.833 & 194 & 1.732 \\
\hline 2018 & PNP & Native & 10 & 0.833 & 188 & 1.679 \\
\hline 2018 & PPY & Native & 12 & 0.999 & 297 & 2.652 \\
\hline 2018 & $\mathrm{HHL}$ & Secondary & 9 & 0.750 & 228 & 2.036 \\
\hline 2018 & ONS & Secondary & 11 & 0.917 & 197 & 1.759 \\
\hline 2018 & PKT & Secondary & 10 & 0.833 & 201 & 1.795 \\
\hline 2018 & CAS & Logging & 9 & 0.750 & 148 & 1.321 \\
\hline 2018 & $\mathrm{MCP}$ & Logging & 6 & 0.500 & 63 & 0.563 \\
\hline 2018 & PUC & Logging & 10 & 0.833 & 155 & 1.384 \\
\hline 2018 & FMP & Plantation & 11 & 0.917 & 179 & 1.598 \\
\hline 2018 & ONP & Plantation & 6 & 0.500 & 50 & 0.446 \\
\hline 2018 & $\mathrm{RCV}$ & Plantation & 8 & 0.667 & 78 & 0.696 \\
\hline
\end{tabular}

PNN Nahuelbuta National Park, PNP Puyehue National Park, PPY Peumayén Park, HHL Huilo Huilo Reserve, ONS Oncol Park (secondary forest), PKT Katalapi Park, CAS Cascadas, MCP Moncopulli, PUC Pucatrihue, FMP Forestal Mininco, ONP Oncol Park (plantation), RCV Valdivian Coastal Reserve 
located camera traps within each site (covering $\sim 1$ ha), placing three cameras per landscape at each monthly rotation (we conducted four rotations each summer). For each sampling year, we had 12 camera-trap points at each sampling site (making a total of 144 camera trap points per year). Our sampling effort consisted of 774,144 monitoring hours in 288 sampling points in both years. We used the information collected by the camera traps to obtain $D$. gliroides occurrence and relative abundance estimations.

We examined camera trap images looking for D. gliroides, pooling the data of both sampling years. As we cannot distinguish individuals from the photographs, we applied a 1-h independence interval to minimize the chance of counting the same individual more than once $[37,47]$. After filtering the information, we estimated $D$. gliroides occurrence as the number of camera-trap points with at least one presence record of this species, divided by the number of camera traps installed. This occurrence index ranges between 0 (i.e., D. gliroides was not recorded at any camera trap) and 1 (i.e., D. gliroides was present on all camera traps). Then, relative abundance was estimated as the number of $D$. gliroides individuals per day.

\section{Landscape characterization}

We assessed landscape configuration at the 12 study landscapes using Google Earth aerial images. We plotted a circular buffer of 4- $\mathrm{km}$ radius from the centroid of the camera-trap monitoring area at each landscape and characterized the different land uses within this buffer in ArcGIS 10.6 (ESRI, Redlands CA). We distinguished the following land uses: native forest, forestry plantations, scrubland, prairie, and households. After that, we used the FRAGSTATS 4 software [21] to calculate landscapelevel metrics (mean values for each site are presented in Table S2). From all the available metrics in FRAGSTS, we selected five metrics based on biological criteria of $D$. gliroides $[35,39]$. From those, we chose two area metrics: PLAND (\% of native forest within the landscape) and NP (number of patches), one shape metric: CONTIG (contiguity index), one isolation metric: ENN (Euclidean distance to the nearest neighbor), and one connectivity metric: CONNECT (connectivity index). For CONTIG and ENN we used the weighted mean estimators. The connectivity index (CONNECT) depends on the threshold distance set a priori for its calculations. In this case, we used $250 \mathrm{~m}$, which corresponds to the half of the maximum movement distance reported for $D$. gliroides $[31,48]$.

\section{Data analysis}

We related $D$. gliroides occurrence and abundance with the landscape metrics obtained with FRAGSTATS using Bayesian Linear Mixed Models (BLMM hereafter).

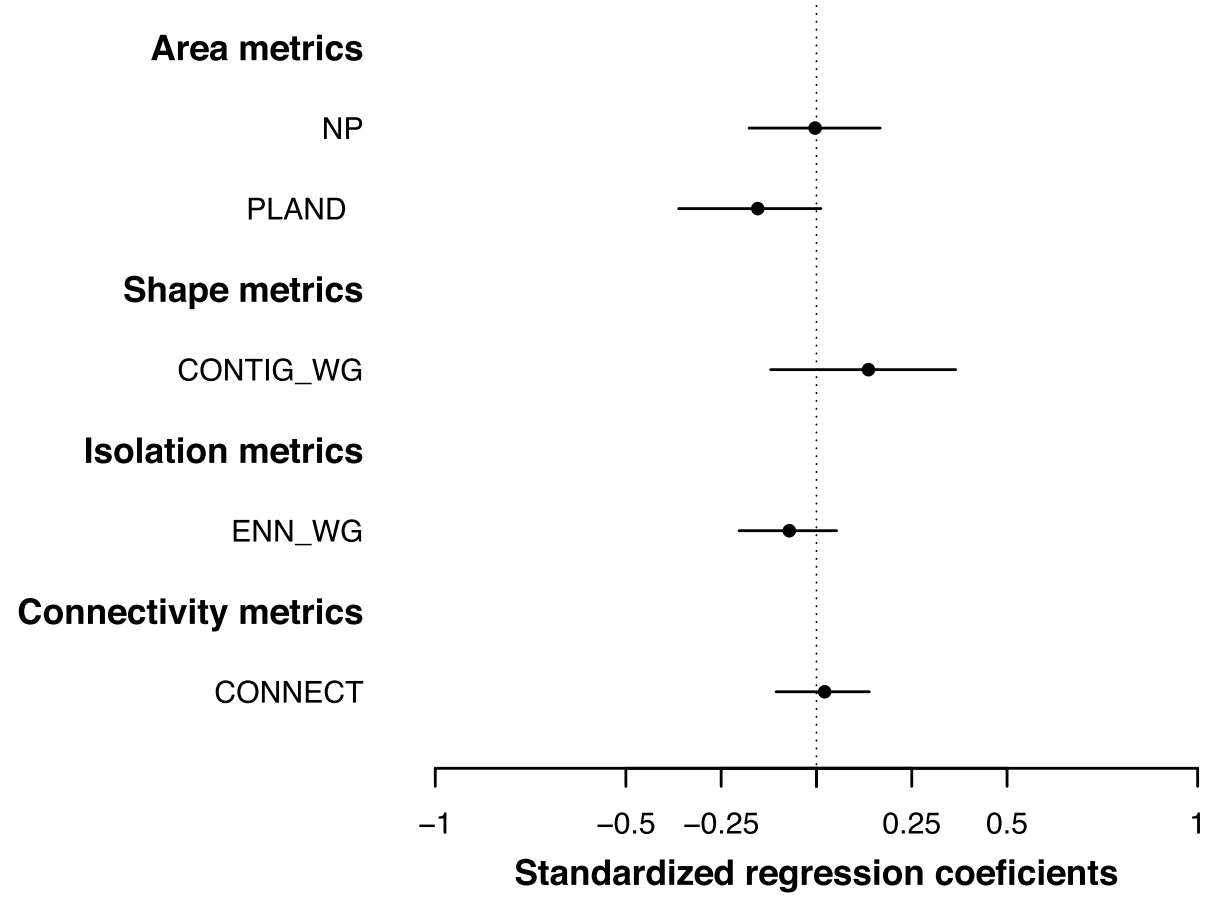

Fig. 1 Confidence intervals of the standardized regression coefficients of the BLMM model relating landscape metrics and Dromiciops gliroides occurrence. The effects of landscape metrics are considered significant when their confidence intervals do not overlap the zero line 
Before fitting the models, we centered and standardized landscape configuration data to make the coefficients comparable. We fitted separate BLMM models for occurrence and abundance data. We used a Gaussian error distribution for each model, including the five landscape metrics obtained from FRAGSTATS as fixed effects. Also, we included the sampling year and habitat disturbance condition as random effects to take temporal and disturbance level variability into account [49]. We performed BLMM analyses in $\mathrm{R}$ 4.0.4 [50] using the R packages 'usdm' [51] and 'MCMCglmm' [52] to implement Bayesian methods, and the 'ggplot2' package [53] for visualization data. We used the default priors in 'MCMCglmm' for fixed and random effects. To obtain a minimum of 1000 posterior distributions, we ran 13,000 iterations for each model, with a burn-in period of 1000 iterations and a thinning interval of 3000 iterations. We considered landscape predictors significant if their 95\% confidence interval did not overlap zero.

\section{Results}

We detected $D$. gliroides in all the sampling landscapes during the study. However, its abundance and occurrence were variable among sites, disturbance conditions, and years (Table 1). Dromiciops gliroides abundance decreased with habitat disturbance (i.e., old-growth forests $>$ secondary forests $>$ logged forests $>$ plantations), and its occurrence at the sampling landscapes varied (a)

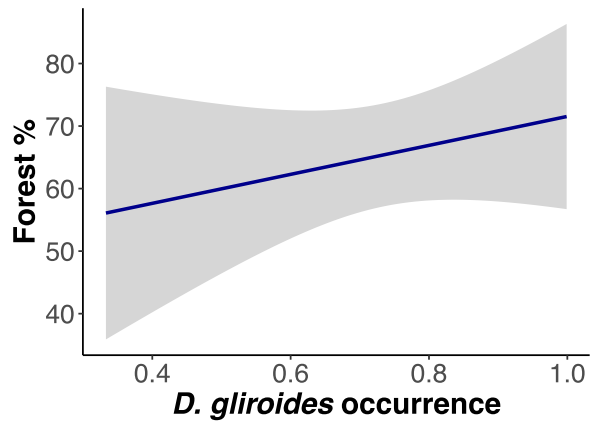

(c)

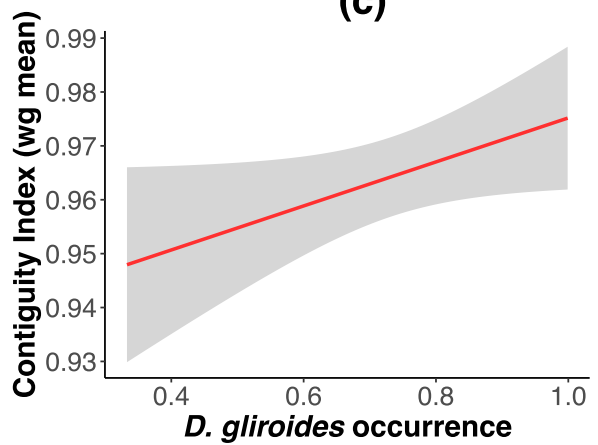

(e)

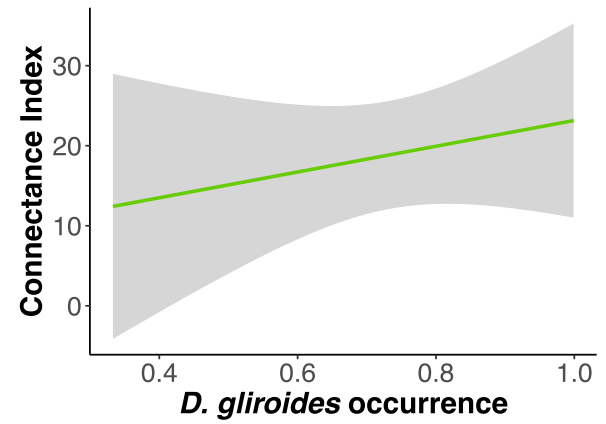

(b)

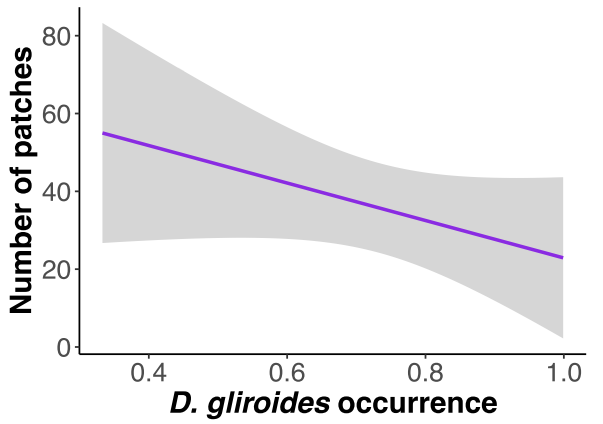

(d)

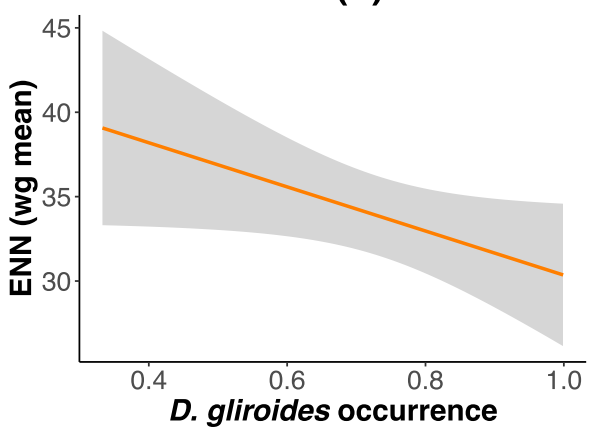

D. gliroides occurrence

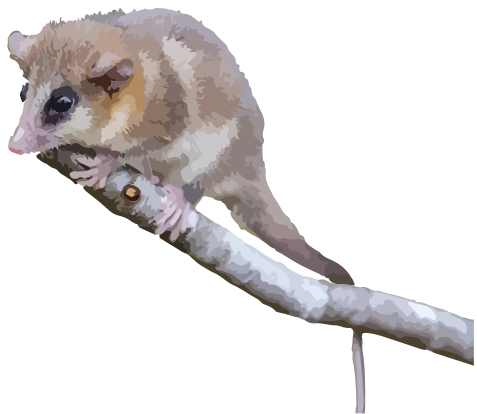

Fig. 2 Linear relationships of landscape metrics and Dromiciops gliroides occurrence. Landscape metrics used: (a) proportion of forest cover in the landscape (PLAND), (b) number of patches (NP), (c) contiguity index (CONTIG, weighted mean), (d) Euclidean distance to the nearest neighbor (ENN, weighted mean), and (e) connectivity index (CONNECT, measured at $250 \mathrm{~m}$ ). Shaded areas represent $95 \%$ confidence intervals 
between 5 and 11 cameras (out of 12) with at least one photographic record of this species. Mean occurrence index (with values ranging from 0 to 1 ) in the first year was $0.69 \pm 0.06$ (mean $\pm \mathrm{SE}$ ), while in the second year was $0.78 \pm 0.05$. The first year our camera trap survey recorded a total of $994 \mathrm{D}$. gliroides individuals (estimated after applying the 1-h independence interval to the raw dataset), and the second year the number of $D$. gliroides individuals was 1978. Thus, D. gliroides relative abundance in the first year was $0.74 \pm 0.09$ individuals / day, while in the second year was $1.47 \pm 0.18$ individuals / day.

Regarding landscape configuration effects on $D . g l i-$ roides occurrence, none of these predictors was significant, but we detected a marginal effect on PLAND (Fig. 1 and Table S3). However, we observe positive trends with PLAND, CONTIG, and CONNECT metrics, and negative trends with NP and ENN (Fig. 2). Regarding landscape configuration effects on $D$. gliroides abundance, we found that CONTIG has a positive and significant effect on D. gliroides abundance (Fig. 3 and Table S4). In this case, we also observe positive trends with PLAND, CONTIG and CONNECT metrics, and negative trends with NP and ENN (Fig. 4).

\section{Discussion}

Our results showed that $D$. gliroides abundance is more sensitive to landscape configuration than its occurrence. Habitat contiguity was the most relevant factor, in this case, explaining the abundance differences found in our camera-trap survey. However, forest proportion in the landscape had a marginal effect in explaining differences in occurrence as well. Therefore, the spatial configuration of the remaining forest patches within the landscape seems to be more relevant than habitat quantity for $D$. gliroides.

As D. gliroides is an arboreal marsupial, it largely depends on the three-dimensional structure of the forest, being unable to move across non-forested areas [31], as it happens with other forest species with restricted dispersal abilities, such as Rhinocryptids [11,30]. Therefore, the proximity among forest patches (quantified using the CONTIG index) may be directly related to dispersal probability, as it reduces the resistance of contrasting matrices (e.g., a grassland). While disturbed habitat can offer complementary resources to D. gliroides (e.g., fruits from shade-intolerant plants; 39), also lack of certain key elements such as tree cavities that are central for nesting in D. gliroides and other bird species $[54,55]$, which may compromise their reproductive success $[16,56]$. Thus, the limited availability of nesting sites in disturbed habitats may be related to lower abundances that we detected in this study. Despite $D$. gliroides is able to nest outside tree cavities when are scarce or absent [57], they are negatively affected by the lack of habitat complexity $[36,40]$ in disturbed habitats.

Besides tree cavities, D. gliroides is often associated with the native bamboo Chusquea quila [58], a major

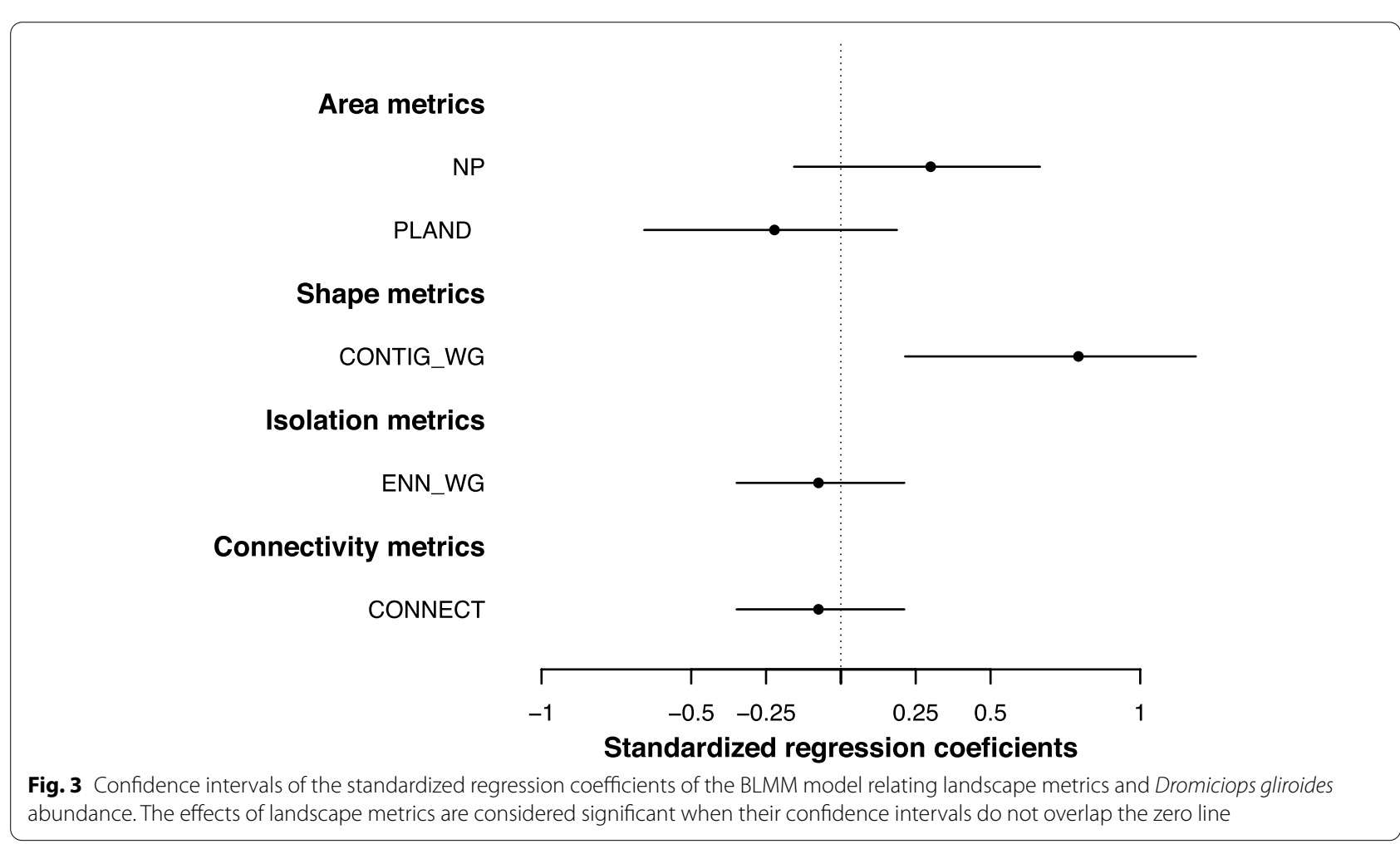


(a)

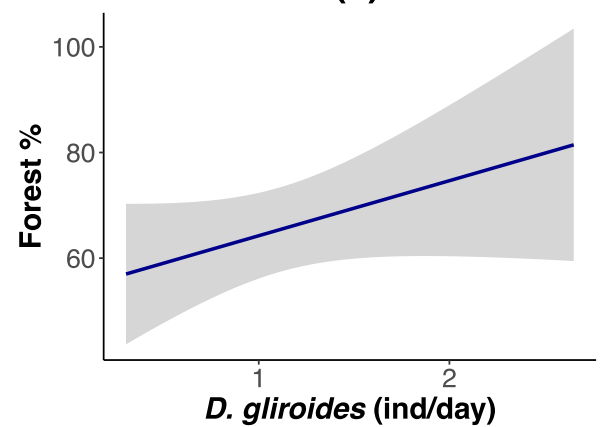

(c)

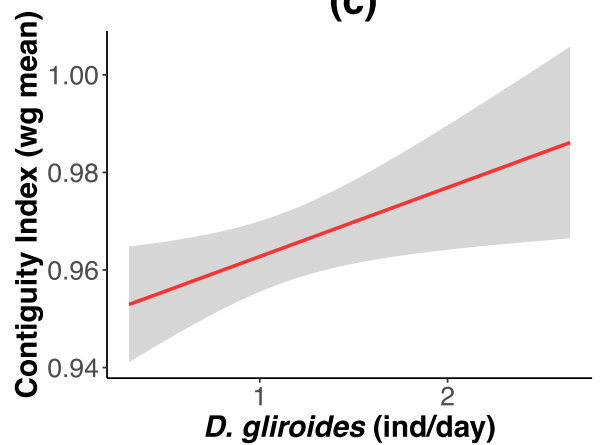

(e)

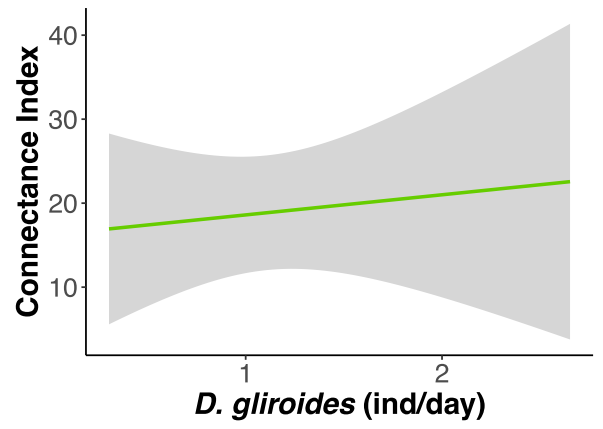

(b)

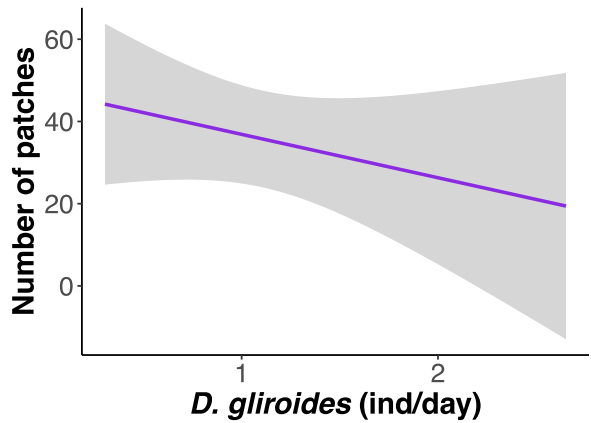

(d)

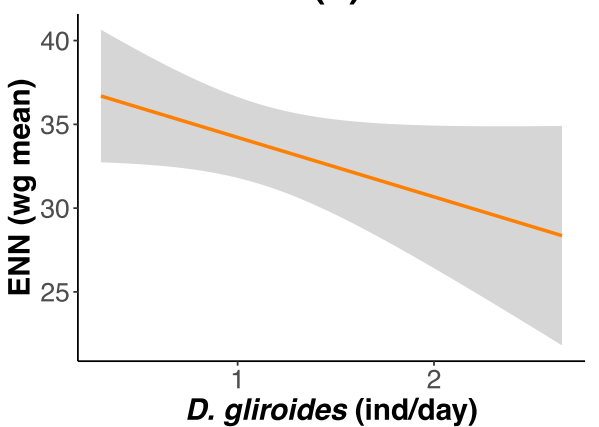

D. gliroides (ind/day)

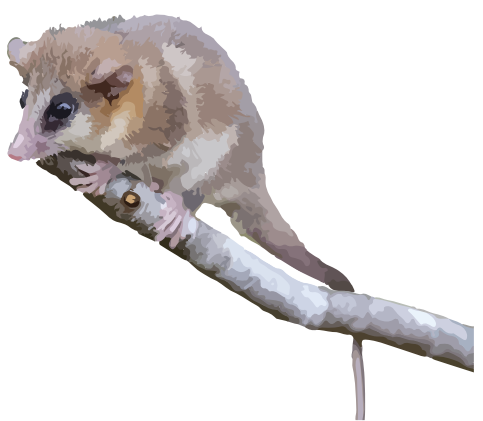

Fig. 4 Linear relationships of landscape metrics and Dromiciops gliroides abundance. Landscape metrics used: (a) proportion of forest cover in the landscape (PLAND), (b) number of patches (NP), (c) contiguity index (CONTIG, weighted mean), (d) Euclidean distance to the nearest neighbor (ENN, weighted mean), and (e) connectivity index (CONNECT, measured at $250 \mathrm{~m}$ ). Shaded areas represent 95\% confidence intervals

component of its nests $[59,60]$. Bamboo cover is also an important habitat feature for understory birds at these forests [56]. Therefore, the occurrence and abundance of D. gliroides across landscapes with different disturbance levels may depend on a multi-scale process, in which local vegetation structure and landscape configuration are relevant to explain the occurrence patterns observed in this study. A mild local disturbance may increase the availability of food resources, with a positive effect on $D$. gliroides occurrence and abundance [41, 61]. However, landscape-level processes are expected to have the opposite effect. For instance, if a fragmented landscape goes into an attrition process (i.e., forest fragments get smaller and more isolated in time), it may outweigh the positive effects of increased resource availability. The challenging task in this regard, is to determine the ecological thresholds of landscape configuration that represent an inflection point from positive to negative effects on biodiversity $[17,62]$. As a habitat become fragmented, positive effects are mainly related to local-scale processes that result in more diverse and abundant resources as a consequence of increased habitat heterogeneity (e.g., 41). On the contrary, negative effects are usually related to landscape-scale processes [63], mainly driven by edge-effects and the loss of functional connectivity among fragments $[9,12,28,36]$. 
Effective conservation actions of forest-dependent animals, such as Dromiciops gliroides, require an integral approach to conserve species by conserving their habitats and interactions. Thus, landscape configuration should also be considered in conservation and management plans, promoting the restoration of functional connectivity among forest remnants. Due to its habitat requirements, D. gliroides is considered as an umbrella species of the Valdivian rainforests [42]. Therefore, managing the extant habitat remnants to fulfill $D$. gliroides' requirements will also protect other forest species (e.g., Rhinocryptid birds) that also benefit from forest contiguity and connectivity $[11,15$, 30]. Also, it is important to stop deforestation as it may be leading to a non-return point for many forest-dependent species.

\section{Conclusions}

Landscape configuration matters. The abundance of the arboreal marsupial Dromiciops gliroides is affected by habitat contiguity, while forest proportion in the landscape had a marginal effect on its occurrence. As D. gliroides is a forest-dependent species, it cannot disperse through non-forested habitats. Therefore, maintaining the contiguity among forest fragments is the most relevant management practice to guarantee its long-term persistence. We urge to rethink native forest conservation and management policies, aimed to improve habitat conditions for native fauna by adequately managing landscape configuration to connect forest remnants.

\section{Abbreviations}

PLAND: \% Of native forest within the landscape; NP: Number of patches; CONTIG: Contiguity index; ENN: Euclidean distance to the nearest neighbor; CONNECT: Connectivity index; BLMM: Bayesian Linear Mixed Models.

\section{Supplementary Information}

The online version contains supplementary material available at https://doi. org/10.1186/s40693-022-00107-9.

Additional file 1: Table S1. Geographic coordinates and habitat condition of the sampled landscapes. Figure S1. Location of the sampling sites along the Valdivian rainforest, indicating the habitat condition of each site. Table S2. Mean values of landscape configuration metrics for each sampled landscape. Table S3. Detailed results of the Bayesian Linear Mixed Model fitted for Dromiciops gliroides occurrence and its relationship with landscape metrics. Table S4. Detailed results of the Bayesian Linear Mixed Model fitted for Dromiciops gliroides abundance and its relationship with landscape metrics.

\section{Acknowledgements}

We are grateful to the Chilean Forestry Corporation (CONAF), the Huilo Huilo Foundation, The Nature Conservancy (Valdivian Coastal Reserve), Oncol Park, Katalapi Park, Peumayén Park, David Carrasco, Bernardo Eggers, and Raúl Las Casas for authorizing sampling at their lands and for the logistic support. Comments of C. Atala and two anonymous reviewers improved an earlier version of the manuscript. This research was funded the ANID-FONDECYT project 11160152 granted by the Chilean Agency of Research and Development
(ANID) to FEF. FEF acknowledges the support of ANID - Millennium Science Initiative Program - NCN2021-050.

Data availability

$\mathrm{R}$ code and original data are freely available from the figshare digital repository: https://doi.org/10.6084/m9.figshare.16649386

Code availability

Figshare digital repository: https://doi.org/10.6084/m9.figshare.16649386

\section{Authors' contributions}

F.E.F. and G.B.R.G. conceived the ideas and designed the methodology. G.B.R.G. and F.E.F. collected field data. V.P.F. and F.E.F. processed field data. V.P.F., D.A.M.M., G.J.C.V. and F.E.F. analyzed data. F.E.F led manuscript writing with contributions of V.P.F., G.B.R.G., and G.J.C.V. The authors read and approved the final manuscript.

\section{Funding}

This research was funded by Fondo Nacional de Desarrollo Científico y Tecnológico (FONDECYT, Chile), grant 11160152 to FEF.

Availability of data and materials

Figshare digital repository: https://doi.org/10.6084/m9.figshare.16649386

\section{Declarations}

Ethics approval and consent to participate

Not applicable.

Consent for publication

Not applicable.

Competing interests

None.

\section{Author details}

${ }^{1}$ Instituto de Biología, Facultad de Ciencias, Pontificia Universidad Católica de Valparaíso, Valparaíso, Chile. ${ }^{2}$ Departamento de Ciencias Ecológicas, Facultad de Ciencias, Universidad de Chile, Santiago, Chile. ${ }^{3}$ Grupo de Investigación en Ecosistemas Tropicales, Facultad de Ciencias Exactas Y Naturales, Universidad de Caldas, Manizales, Colombia. ${ }^{4}$ Grupo de Investigación GEBIOME and Departamento de Desarrollo Rural Y Recursos Naturales, Facultad de Ciencias Agropecuarias, Universidad de Caldas, Manizales, Colombia. ${ }^{5}$ Millennium Nucleus of Patagonian Limit of Life (LiLi), Valdivia, Chile.

Received: 4 October 2021 Accepted: 17 January 2022

Published online: 22 January 2022

References

1. Fahrig L. Effects of habitat fragmentation on biodiversity. Annu Rev Ecol Syst. 2003;34:487-515.

2. Franklin AB, Noon BR, George TL. What is habitat fragmentation? Studies in Avian Biology. 2002;25:20-9.

3. Haddad NM, Brudvig LA, Clobert J, Davies KF, Gonzalez A, Holt RD, et al Habitat fragmentation and its lasting impact on Earth's ecosystems. Sci Adv. 2015;1(2):e1500052.

4. Ricketts TH. The matrix matters: effective isolation in fragmented landscapes. Am Nat. 2001;158(1):87-99.

5. Driscoll DA, Banks SC, Barton PS, Lindenmayer DB, Smith AL. Conceptual domain of the matrix in fragmented landscapes. Trends Ecol Evol. 2013;28(10):605-13.

6. Harrison S, Bruna E. Habitat fragmentation and large-scale conservation: what do we know for sure? Ecography. 1999:22:225-32.

7. Vergara PM, Simonetti JA. Forest fragmentation and rhinocryptid nest predation in central Chile. Acta Oecol. 2003;24(5-6):285-8.

8. Fischer J, Lindenmayer DB. Landscape modification and habitat fragmentation: a synthesis. Global Ecol Biogeogr. 2007:16(3):265-80. 
9. Willson MF. Loss of habitat connectivity hinders pair formation and juvenile dispersal of Chucao Tapaculos in Chilean rainforest. Condor. 2004;106(1):166-71.

10. Willson MF, Desanto TI, Sabag C, Armesto JJ. Avian communities of fragmented south-temperate rainforests in Chile. Conserv Biol. 1994;8(2):508-20.

11. Sieving KE, Willson MF, DeSanto TL. Habitat barriers to movement of understory birds in fragmented south-temperate rainforest. Auk. 1996;113(4):944-9.

12. Uezu A, Metzger JP, Vielliard JME. Effects of structural and functional connectivity and patch size on the abundance of seven Atlantic Forest bird species. Biol Conserv. 2005;123(4):507-19.

13. Johnstone CP, Lill A, Reina RD. Habitat loss, fragmentation and degradation effects on small mammals: Analysis with conditional inference tree statistical modelling. Biol Conserv. 2014;176:80-98.

14. Ghazoul J, Burivalova Z, Garcia-Ulloa J, King LA. Conceptualizing Forest Degradation. Trends Ecol Evol. 2015;30(10):622-32.

15. Diaz IA, Armesto JJ, Reid S, Sieving KE, Willson MF. Linking forest structure and composition: avian diversity in successional forests of Chiloé Island. Chile Biol Conserv. 2005;123(1):91-101.

16. Diaz IA, Armesto JJ, Willson MF. Mating success of the endemic Des Murs'Wiretail (Sylviorthorhynchus desmursii, Furnariidae) in fragmented Chilean rainforests. Austral Ecol. 2006;31:13-21.

17. Ewers RM, Didham RK. Confounding factors in the detection of species responses to habitat fragmentation. Biol Rev. 2006;81(1):117-42.

18. Fletcher RJ, Didham RK, Banks-Leite C, Barlow J, Ewers RM, Rosindell J, et al. Is habitat fragmentation good for biodiversity? Biol Conserv. 2018;226:9-15.

19. Cushman SA, McGariyal K, Neel MC. Parsimony in landscape metrics: Strength, universality, and consistency. Ecol Indic. 2008;8(5):691-703.

20. Herzog F, Lausch A, Muller E, Thulke HH, Steinhardt U, Lehmann S. Landscape metrics for assessment of landscape destruction and rehabilitation. Environ Manage. 2001;27(1):91-107.

21. McGarigal K, Cushman SA, Ene E. FRAGSTATS v4: Spatial Pattern Analysis Program for Categorical and Continuous Maps. Amherst MA: University of Massachusetts; 2012.

22. Henle K, Davies KF, Kleyer M, Margules C, Settele J. Predictors of species sensitivity to fragmentation. Biodivers Conserv. 2004;13(1):207-51.

23. Myers N, Mittermier RA, Mittermier CG, da Fonseca GAB, Kent J. Biodiversity hotspots for conservation priorities. Nature. 2000;403(24):853-8.

24 Mittermier RA, Gil PR, Hoffman M, Pilgrim J, Brooks T, Mittermier CG, et al. Hotspots revisited: Earth's biologically richest and most threatened terrestrial regions. Monterrey, Mexico: Cemex; 2005.

25. Echeverría C, Coomes D, Salas J, Rey-Benayas JM, Lara A, Newton A. Rapid deforestation and fragmentation of Chilean temperate forest. Biol Conserv. 2006;130(4):481-94.

26. Echeverría C, Newton A, Lara A, Rey-Benayas JM, Coomes D. Impact of forest fragmentation on species composition and forest structure in the temperate landscape of southern Chile. Glob Ecol Biogeogr. 2007; 16:426-39.

27. Heinrichs S, Pauchard A, Schall P. Native plant diversity and composition across a Pinus radiata D.Don plantation landscape in south-central Chile: The impact of plantation age, logging roads and alien species. Forests. 2018;9(9):art567.

28. Castillo MG, Hernandez HJ, Estades CF. Effect of connectivity and habitat availability on the occurrence of the Chestnut-throated Huet-Huet (Pteroptochos castaneus, Rhinocryptidae) in fragmented landscapes of central Chile. Landscape Ecol. 2018;33(7):1061-8.

29. Castellón TD, Sieving KE. Patch network criteria for dispersal-limited endemic birds of South American temperate rain forst. Ecol Appl. 2007;17:2152-63.

30. Sieving KE, Willson MF, De Santo TL. Defining corridor functions for endemic birds in fragmented south-temperate rainforest. Conserv Biol. 2000;14(4):1120-32.

31. Fontúrbel FE, Silva-Rodríguez EA, Cárdenas NH, Jiménez JE. Spatial ecology of monito del monte (Dromiciops gliroides) in a fragmented landscape of southern Chile. Mamm Biol. 2010;75(1):1-9.

32. Didham RK, Kapos V, Ewers RM. Rethinking the conceptual foundations of habitat fragmentation research. Oikos. 2012;121(2):161-70.

33 Hershkovitz P. Dromiciops gliroides Thomas, 1894, last of the Microbiotheria (Marsupialia), with a review of the family Microbiotheriidae. Fieldiana: Zoology. 1999;93:1-60.
34. Amico GC, Rodríguez-Cabal MA, Aizen MA. The potential key seeddispersing role of the arboreal marsupial Dromiciops gliroides. Acta Oecol. 2009:35:8-13.

35. Fontúrbel FE, Franco M, Rodríguez-Cabal MA, Rivarola MD, Amico GC. Ecological consistency across space: a synthesis of the ecological aspects of Dromiciops gliroides in Argentina and Chile. Naturwissenschaften. 2012;99:873-81.

36. Rodríguez-Cabal MA, Aizen MA, Novaro AJ. Habitat fragmentation disrupts a plant-disperser mutualism in the temperate forest of South America. Biol Conserv. 2007;139(1):195-202.

37. Fontúrbel FE, Candia AB, Botto-Mahan C. Nocturnal activity patterns of the monito del monte (Dromiciops gliroides) in native and exotic habitats. J Mammal. 2014;95(6):1199-206.

38. Uribe SV, Chiappe RG, Estades CF. Persistence of Dromiciops gliroides in landscapes dominated by Pinus radiata plantations. Rev Chil Hist Nat. 2017;90:art2.

39. Salazar DA, Fontúrbel FE. Beyond habitat structure: Landscape heterogeneity explains the monito del monte (Dromiciops gliroides) occurrence and behavior at habitats dominated by exotic trees. Integr Zool. 2016:11:413-21.

40. Rodríguez-Gómez GB, Fontúrbel FE. Regional-scale variation on Dromiciops gliroides occurrence, abundance, and activity patterns along a habitat disturbance gradient. J Mammal. 2020;101(3):733-41.

41. Fontúrbel FE, Salazar DA, Medel R. Increased resource availability prevents the disruption of key ecological interactions in disturbed habitats. Ecosphere. 2017;8(4):e01768.

42. Fontúrbel FE, Jiménez JE. Environmental and ecological architects: Guidelines for the Chilean temperate rainforest management derived from the monito del monte (Dromiciops gliroides) conservation. Rev Chil Hist Nat. 2011;84(2):203-11.

43. Mejías C, Castro-Pastene CA, Carrasco H, Quintero-Galvis JF, Soto-Gamboa M, Bozinovic F, et al. Natural history of the relict marsupial Monito del Monte at the most extreme altitudinal and latitudinal location. Ecosphere. 2021;12(6):e03577.

44. Oda E, Rodríguez-Gómez GB, Fontúrbel FE, Soto-Gamboa M, Nespolo RF. Southernmost records of Dromiciops gliroides: extending its distribution beyond the Valdivian rainforest. Gayana. 2019;83:145-9.

45. Quintero-Galvis JF, Saenz-Agudelo P, Celis-Diez JL, Amico GC, Vazquez MS, Shafer ABA, et al. The biogeography of Dromiciops in southern South America: Middle Miocene transgressions, speciation and associations with Nothofagus. Mol Phylogenet Evol. 2021;163:107234.

46. D'Elia G, Hurtado N, D'Anatro A. Alpha taxonomy of Dromiciops (Microbiotheriidae) with the description of 2 new species of monito del monte. J Mammal. 2016;97(4):1136-52.

47. Oliveira-Santos LGR, Tortato MA, Graipel ME. Activity pattern of Atlantic Forest small arboreal mammals as revealed by camera traps. J Trop Ecol. 2008:24:563-7.

48. Franco LM, Fontúrbel FE, Guevara G, Soto-Gamboa M. Movement behavior of the Monito del monte (Dromiciops gliroides): new insights into the ecology of a unique marsupial. Rev Chil Hist Nat. 2019;92(1):art 8.

49. Schielzeth $\mathrm{H}$. Simple means to improve the interpretability of regression coefficients. Methods Ecol Evol. 2010;1(2):103-13.

50. R Development Core Team. R: A language and environment for statistical computing, reference index version 4.0.4. Vienna, Austria: Foundation for Statistical Computing; 2021.

51. Naimi B. usdm: uncertainty analysis for species distribution models. $R$ package version 11-15 R. 2010.

52. Hadfield JD. MCMC methods for multi-response Generalized Linear Mixed Models: The MCMCgImm R package. J Stat Softw. 2010;33(1):1-22.

53. Wickham H. ggplot2: elegant graphics for data analysis. New York: Springer; 2016.

54. Castellón TD, Sieving KE. Landscape history, fragmentation, and patch occupancy: models for a forest bird with limited dispersal. Ecol Appl. 2006;16(6):2223-34

55. Celis-Diez JL, Hetz J, Marín-Vial PA, Fuster G, Necochea P, Vásquez RA, et al. Population abundance, natural history, and habitat use by the arboreal marsupial Dromiciops gliroides in rural Chiloé Island. Chile J Mammal. 2012;93(1):134-48.

56. Reid S, Diaz IA, Armesto JJ, Willson MF. Importance of native bamboo for understory birds in Chilean temperate forests. Auk. 2004;121(2):515-25. 
57. Vazquez MS, Ibarra JT, Altamirano TA. Austral Opossum adjusts to life in second-growth forests by nesting outside cavities. Austral Ecol. 2020;45(8):1179-82.

58. Rodríguez-Cabal MA, Branch LC. Influence of habitat factors on the distribution and abundance of a marsupial seed disperser. J Mammal. 2011;92(6):1245-52.

59. Franco M, Quijano SA, Soto-Gamboa M. Communal nesting, activity patterns, and populations characteristics in the near-threatened monito del monte. Dromiciops gliroides J Mammal. 2011;92(5):994-1004.

60. Honorato MT, Altamirano TA, Ibarra JT, De la Maza M, Bonacic C, Martin K. Composition and preferences regarding nest materials by cavitynesting vertebrates in the Andean temperate forest of Chile. Bosque. 2016;37(3):485-92.

61. H González-Ancin, M Spinola, JM Mora-Benavides, JC Sáenz, A Paillacar, FE Fontúrbel. 2021. Intermediate levels of wood extraction may facilitate coexistence of an endemic arboreal marsupial and Indigenous communities. Oryx. https://doi.org/10.1017/S003060532000109.

62. Didham RK, Ewers RM. Predicting the impacts of edge effects in fragmented habitats: Laurance and Yensen's core area model revisited. Biol Conserv. 2012;155:104-10.

63. Kindlmann P, Burel F. Connectivity measures: a review. Landscape Ecol. 2008:23(8):879-90.

\section{Publisher's Note}

Springer Nature remains neutral with regard to jurisdictional claims in published maps and institutional affiliations.

- fast, convenient online submission

- thorough peer review by experienced researchers in your field

- rapid publication on acceptance

- support for research data, including large and complex data types

- gold Open Access which fosters wider collaboration and increased citations

- maximum visibility for your research: over 100M website views per year

At BMC, research is always in progress.

Learn more biomedcentral.com/submissions 